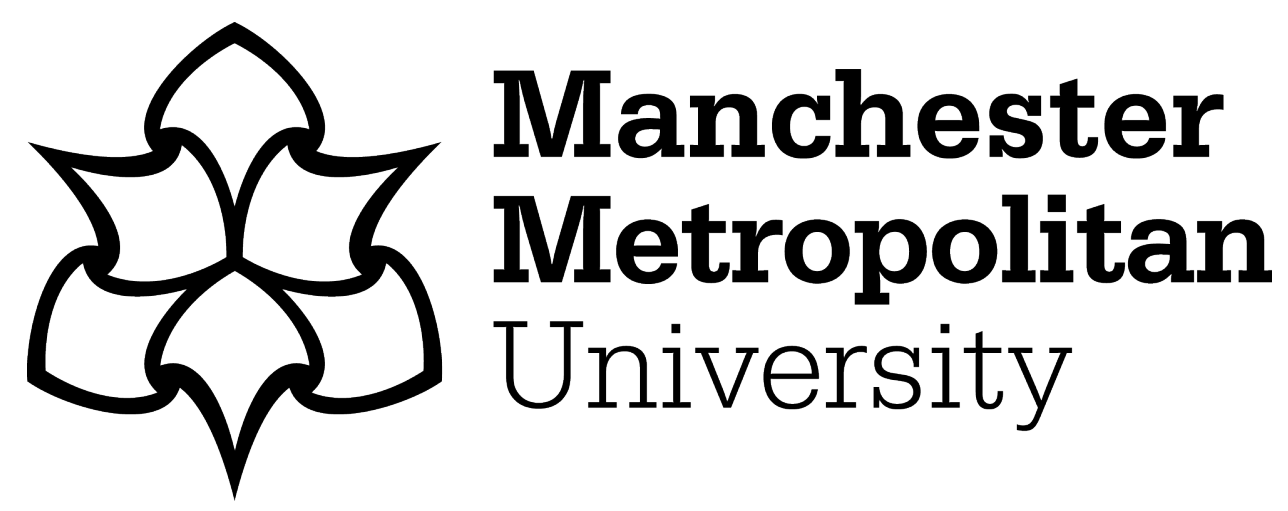

Bagley, L, McPhee, JS, Ganse, B, Müller, K, Korhonen, MT, Rittweger, J and Degens, $H$ (2019) Similar relative decline in aerobic and anaerobic power with age in endurance and power master athletes of both sexes. Scandinavian journal of medicine \& science in sports, 29 (6). pp. 791-799. ISSN 0905-7188

Downloaded from: https://e-space.mmu.ac.uk/622550/

Version: Accepted Version

Publisher: Wiley

DOI: https://doi.org/10.1111/sms.13404

Please cite the published version 
1

2

3

4

$5{ }^{1}$ : School of Healthcare Science, Manchester Metropolitan University, Manchester, UK; ${ }^{2}$ :

6 Department of Sport and Exercise Sciences, Manchester Metropolitan University,

7 Manchester, UK; ${ }^{3}$ :Department of Orthopaedic Trauma; RWTH Aachen University Hospital;

8 Aachen; Germany; ${ }^{4}$ : Institute of Aerospace Medicine; German Aerospace Center; Cologne;

9 Germany; ${ }^{5}$ : Gerontology Research Center; Faculty of Sport and Health Sciences; University of 10 Jyväskylä; Finland; ${ }^{6}$ : Department of Pediatrics and Adolescent Medicine, University of 11 Cologne, Cologne, Germany, ${ }^{7}$ : Institute of Sport Science and Innovations; Lithuanian Sports 12

M1 5GD, Manchester

23 UK

24

Tel: +441612471145

Running title: Anaerobic and aerobic power in master athletes

Address for correspondence:

Dr L. Bagley

School of Healthcare Science

Manchester Metropolitan University

E-mail: Liam.Bagley@mmu.ac.uk 
ABSTRACT

27 Lower physical activity levels in old age are thought to contribute to the age-related decline in peak aerobic and anaerobic power. Master athletes maintain high levels of physical activity with advancing age and endurance or power training may influence the extent to which these physical functions decline with advancing age. To investigate, 37-90-year-old power $(n=20$, $45 \%$ female) and endurance ( $n=19,58 \%$ female) master athletes were recruited. Maximal aerobic power was assessed when cycling two-legged $\left(\mathrm{VO}_{2} \mathrm{Peak}_{2-\mathrm{leg}}\right)$ and cycling one-legged ( $\mathrm{VO}_{2}$ Peak $_{1-\mathrm{leg}}$ ), while peak jumping (anaerobic) power was assessed by a countermovement jump. Men and women had a similar $\mathrm{VO}_{2}$ Peak $_{2}$ leg $\left(\mathrm{mL} \cdot \mathrm{kg}^{-1} \cdot \mathrm{min}^{-1}, \mathrm{p}=0.138\right)$ and similar ratio of $\mathrm{VO}_{2}$ Peak $_{1-\text { leg }}$ to $\mathrm{VO}_{2}$ Peak $_{2 \text {-leg }}(\mathrm{p}=0.959)$ and similar ratio of peak aerobic to anaerobic power $(p=0.261)$. The $\mathrm{VO}_{2}$ Peak $_{2-\operatorname{leg}}\left(\mathrm{mL} \cdot \mathrm{kg}^{-1} \cdot \mathrm{min}^{-1}\right)$ was $17 \%(p=0.022)$ and the peak rate of fat oxidation (FATmax) during steady-state cycling was $45 \%$ higher in endurance than power athletes $(p=0.001)$. The anaerobic power was 33\% higher in power than endurance athletes $(p=0.022)$. The $\mathrm{VO}_{2} \mathrm{Peak}_{1-\mathrm{leg}}: \mathrm{VO}_{2} \mathrm{Peak}_{2 \text {-leg }}$ ratio did not differ significantly between disciplines, but the aerobic to anaerobic power ratio was $40 \%$ higher in endurance than power athletes $(p=0.002)$. Anaerobic power, $\mathrm{VO}_{2} \mathrm{Peak}_{2-\mathrm{leg}}, \mathrm{VO}_{2} \mathrm{Peak}_{1-\mathrm{leg}}$ and power at FATmax decreased by around $7-14 \%$ per decade in male and female power and endurance athletes.

43 The cross-sectional data from 37-90-year-old master athletes in the present study indicates 44 that peak anaerobic and aerobic power decline by around 7-14\% per decade and this does not differ between athletic disciplines or sexes.

Key words: master athletes, ageing, fatty acid oxidation, $\mathrm{VO}_{2}$ Peak 


\section{Introduction}

50 Ageing is accompanied by a progressive decline in bodily functions, ultimately resulting in 51 death ${ }^{[1]}$. Such age-related decrements include a decrease in muscle mass, strength and power generating capacity ${ }^{[2]}$, and reductions in aerobic fitness ${ }^{[3]}$. Similar changes are also seen during disuse ${ }^{[4]}$. It is thus likely that the reduction in physical activity in old age ${ }^{[5]}$ contributes significantly to the age-related reduction in muscle power and maximal oxygen uptake.

Master athletes maintain high levels of physical activity into old age ${ }^{[6]}$ and show impressive athletic feats ${ }^{[7]}$ such as a 97-year-old man still cycling 5,000 km a year ${ }^{[8]}$. They have better physiological function ${ }^{[9]}$, longer lifespan, lower hospitalisation ${ }^{[10]}$ and better quality of life in comparison to sedentary people of the same age ${ }^{[11]}$. Thus, regular exercise helps to combat the effects of ageing ${ }^{[12]}$ and this provides an opportunity to distinguish the effects of ageing per se from the age-related reductions in physical activity ${ }^{[7]}$.

Low cardiopulmonary fitness and neuromuscular function, and high body fatness are common features of ageing and risk factors for disability and all-cause mortality ${ }^{[13,14]}$. These changes are not only due to low activity levels, since even in master athletes, performance levels, cardiopulmonary fitness and neuromuscular function decline ${ }^{[15-18]}$. However, endurance and power training impose different stresses upon cardiopulmonary and neuromuscular systems, with for instance higher ground reaction forces produced during higher running speeds such as when sprinting ${ }^{[19,20]}$.

It remains unknown whether the characteristics that determine power performance, such as very high peak muscle power, decline with ageing at different rates from those that determine endurance performance, such as high cardiopulmonary fitness and muscle aerobic potential.

Given that endurance and power training promote divergent adaptations, such as increased skeletal muscle cross-sectional area and power in power athletes [21], and increased cardiorespiratory fitness, oxidative and fat oxidation capacity in endurance athletes ${ }^{[22,23]}$, we

77 hypothesised that the anaerobic power is better preserved during ageing in power than endurance athletes, while the aerobic and fat oxidation capacity is better preserved in endurance athletes. 
80

81

82 83 84 85 86

87 88 89 90

\section{Methods}

\section{Participants}

The study conformed to the latest revisions of the Declaration of Helsinki ${ }^{[24]}$ and was approved by the Ärztekammer Nordrhein ethics committee, Düsseldorf, Germany (number 2012157). Volunteers were recruited and assessed at the $18^{\text {th }}$ European Veterans Athletics Championships (EVACs) at Weinau Stadium, Zittau, Germany between 16-25 August 2012.

Volunteers provided written informed consent prior to participation. Those with a history of cardiovascular, neuromuscular or metabolic disease, or those who had a leg fracture in the past two years were excluded from the study. Participants were grouped into endurance and power disciplines by their primary entered events. Running events $\geq 800 \mathrm{~m}$ were classified as endurance, and $\leq 400 \mathrm{~m}$ and throwers were classified as power athletes (according to IAAF classifications: https://www.iaaf.org/disciplines). The age-graded performance for the main event of each athlete was calculated using the World Master Athletics age-grading calculator: http://www.howardgrubb.co.uk/athletics/wmalookup06.html. Participant characteristics are shown in Table 1.

\section{Experiments}

Peak jumping (anaerobic) power: Peak jumping power as a measure of peak anaerobic power ${ }^{[20]}$ was assessed in 29 athletes on a Leonardo force platform (Novotec Medical, Pforzheim, Germany). The participants were instructed to perform a two-legged countermovement jump with the aim to raise the head and trunk as far as possible while freely moving their arms. Participants made two or three submaximal jumps to acquaint themselves with the procedure. They then performed three maximal efforts, each separated by $60 \mathrm{~s}$ rest and the attempt that gave the highest power (W) was recorded. The system computed the take-off velocity from the ground reaction force as described by Cavagna ${ }^{[25]}$. Instantaneous power was calculated as the product of force and velocity: Power $(\mathrm{W})=$ Force $(\mathrm{N}) \times$ Velocity $\left(\mathrm{m} \cdot \mathrm{s}^{-1}\right)$.

$\mathrm{VO}_{2}$ Peak $_{2 \text {-leg }}$ (aerobic power): $\mathrm{VO}_{2}$ Peak $_{2-l e g}$ was determined on a cycle ergometer (Jaeger Ergocycle) with a MetaLyzer 3B - R2 (Cortex BioPhysik GmbH, Leipzig, Germany) to measure $\mathrm{VO}_{2}$ and $\mathrm{VCO}_{2}$. Participants started to cycle at a workload of $50 \mathrm{~W}$ and a cadence of $70 \mathrm{rpm}$. 
110 Workload was increased every 3 min with $50 \mathrm{~W}$ for men and $30 \mathrm{~W}$ for women until the 111 respiratory exchange ratio was higher than 1.0 for at least $1 \mathrm{~min}$. From this point onwards, 112 workload was increased by $20 \mathrm{~W}$ every minute until the age-predicted HRmax (220 - age) was 113 exceeded, if the participant reached volitional exhaustion and/or the respiratory exchange 114 ratio was $>1.1$. Heart rate was measured using a Polar heart rate monitor (Polar Oy, Kempele, 115 Finland). The assessment was followed by a 5-min cool down at low cadence ( $40 \mathrm{rpm}$ ) and 116 workload $(25-75 \mathrm{~W})$. The average of the values in the last 30 seconds of the last step was

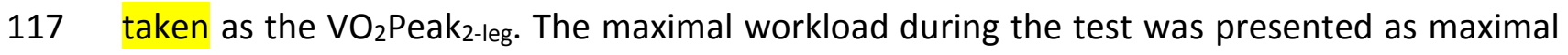
118 aerobic power.

119

120 FATmax (maximal fatty acid oxidation): The rate of fatty acid oxidation was estimated for 121 each workload as described previously [26]: Rate of Fatty Acid Oxidation $\left(\mathrm{g} \cdot \mathrm{min}^{-1}\right)=\left(1.695 \times \mathrm{VO}_{2}\right)-\left(1.701 \times \mathrm{VCO}_{2}\right)$

123 Where $\mathrm{VO}_{2}$ and $\mathrm{VCO}_{2}$ are given in $\mathrm{L} \cdot \mathrm{min}^{-1}$ and negligible urinary nitrogen excretion is assumed.

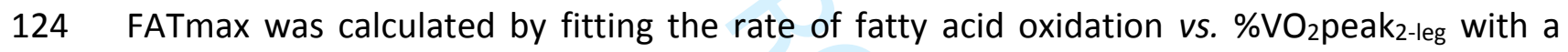
125 polynomial, where the peak of the line was considered the maximal rate of fatty acid 126 oxidation.

$\mathrm{VO}_{2}$ Peak $k_{1-\text { leg }}$ : The $\mathrm{VO}_{2}$ Peak $_{1-\text { leg }}$ during one-leg cycling was measured on a separate day from 129 all other assessments in a subgroup of 18 participants with the same equipment and 130 calibrations as the $\mathrm{VO}_{2}$ Peak $_{2}$-leg assessment. This assessment was included to estimate the 131 peak aerobic capacity of the active leg muscles. Where $\mathrm{VO}_{2}$ Peak $_{2}$-leg may be limited by the 132 cardio-respiratory supply of oxygen to the working muscles and/or by the uptake and 133 utilisation of available oxygen within muscle fibres ${ }^{[27,28]}$, the cardio-respiratory supply of 134 oxygen to active leg muscles during one-legged cycling is not generally limiting. Therefore, 135 the $\mathrm{VO}_{2}$ Peak $_{1-\text { leg }}$ more closely represents the leg muscle peak aerobic potential[ ${ }^{[29]}$.

136 For this assessment, the dominant leg was secured to the pedal on the cycle ergometer, while 137 the non-exercising leg was positioned on a central platform on the cycle ergometer to limit 138 extraneous movements. The participants were asked to minimise upper body movement 139 during the exercise. The workload began at $20 \mathrm{~W}$ at $70 \mathrm{rpm}$ for the first two minutes of the 140 test, after which the workload was increased to $50 \mathrm{~W}$ for one minute and then by $10 \mathrm{~W}$ per 141 minute until volitional exhaustion or a cadence of $70 \mathrm{rpm}$ could not be maintained. The 5 | P a g e 
$142 \mathrm{VO}_{2} \mathrm{Peak}_{1-\mathrm{leg}}\left(\mathrm{L} \cdot \mathrm{min}^{-1}\right)$ was taken as the highest value of $30 \mathrm{~s}$ rolling averages, which in all cases 143 occurred during the final minute of exercise.

\section{Statistical analysis}

146 Data were analysed using SPSS (v.24 IBM). A two-factor ANOVA was used with sex and athletic 147 discipline (power vs. endurance) as between-factors. A discipline*sex interaction indicates 148 that the effect of athletic discipline differs between men and women, determined by an 149 additional post hoc independent samples t-test. A stepwise linear regression was performed 150 with factors age, sex and discipline to assess the impact of these variables on the outcome 151 measures, with adjusted R-values presented. Age-related changes in ratios of jumping power 152 to $\mathrm{VO}_{2}$ Peak 2 -leg, FATmax and the ratio of $\mathrm{VO}_{2}$ Peak $_{1-\text { leg: }} \mathrm{VO}_{2}$ Peak $_{2}$-leg were also analysed by this 153 method. Statistical significance was accepted at $p<0.05$. Data are presented as mean ( \pm SEM) 154 unless stated otherwise.

156 Results

157 Participant characteristics

158 Participant characteristics are shown in Table 1. There was no significant difference in the age 159 of the endurance and power athletes. Men were taller and had a larger body mass than 160 women $(p<0.001)$. The body mass of the power athletes was larger than that of endurance 161 athletes $(p=0.001)$. The BMI was higher in power than endurance athletes $(p=0.001)$, but did 162 not differ significantly between men and women $(p=0.061)$. The AGP did not differ 163 significantly between athletic discipline or between the sexes $(p=0.973$ and $p=0.718$, 164 respectively).

165

166 Jumping (anaerobic) power

167 Men achieved a 64\% higher jumping power than women (Table 2; $p=0.002$ ). However, when 168 normalised to body mass, there was no longer a difference between the sexes in peak jumping 169 power (Table 2; $p=0.070$ ). Power athletes achieved $58 \%$ higher power during vertical jumps 170 compared with long distance runners (Table 2; $\mathrm{p}=0.003$ ) and $33 \%$ higher power than distance 171 runners when normalised to body mass (Table $2 ; p=0.022$ ). The take-off velocity from the 
172 jump was $19 \%$ higher in men than women (Table 2; $p=0.004$ ), and was $15 \%$ higher in power 173 than endurance athletes (Table $2 ; p=0.027$ ).

174

$175 \mathrm{VO}_{2}$ Peak 2 -leg

176 Men displayed a $38 \%$ higher $\mathrm{VO}_{2}$ Peak $_{2-\operatorname{leg}}\left(L \cdot \mathrm{min}^{-1}\right)$ than women (Table $\left.2 ; \mathrm{p}=0.001\right)$, but this 177 difference disappeared when normalised to body mass $\left(\mathrm{mL} \cdot \mathrm{kg}^{-1} \cdot \mathrm{min}^{-1}\right)$ (Table $\left.2 ; \mathrm{p}=0.138\right)$. $178 \mathrm{VO}_{2} \mathrm{Peak}_{2-\mathrm{leg}}\left(\mathrm{L} \cdot \mathrm{min}^{-1}\right)$ did not differ significantly between power and endurance athletes 179 (Table 2; $p=0.592$ ), but when expressed per body mass it was $17 \%$ higher in endurance 180 athletes (Table 2; $\mathrm{p}=0.022$ ). Power (W) at $\mathrm{VO}_{2} \mathrm{Peak}_{2-\operatorname{leg}}$ was $37 \%$ higher in men than women 181 $(p=0.024)$, but did not differ between power and endurance athletes $(p=0.817)$.

182

183 FATmax

184 There was a sex * discipline interaction for FATmax $\left(g \cdot \mathrm{min}^{-1}: \mathrm{p}=0.027 ; \mathrm{mg} \cdot \mathrm{kg} \cdot \mathrm{min}^{-1}: \mathrm{p}=0.019\right)$ 185 which was reflected by a higher FATmax $\left(\mathrm{mg} \cdot \mathrm{kg} \cdot \mathrm{min}^{-1}\right)$ in endurance than power athletes in 186 men $(p<0.001)$, but not in women $(p=0.529)$ and a similar FATmax $\left(\mathrm{mg} \cdot \mathrm{kg} \cdot \mathrm{min}^{-1}\right)$ in male and 187 female endurance athletes $(p=0.121)$ and male and female power athletes $(p=0.067)$ (Table 188 2; Figure 1). There were no effects of $\operatorname{sex}(p=0.964)$ or discipline $(p=0.144)$ on the percentage 189 of $\mathrm{VO}_{2}$ Peak $_{2 \text {-leg }}$ at which FATmax occurred.

190

$191 \mathrm{VO}_{2}$ Peak $_{1-\operatorname{leg}}\left(\mathrm{L} \cdot \mathrm{min}^{-1}\right)$

$192 \mathrm{VO}_{2}$ Peak $_{1-\operatorname{leg}}$ was similar in men and women $(\mathrm{p}=0.159)$, and in endurance and power athletes $193(p=0.431)$. During the single-leg cycling tests, $H_{\text {Peak }}$ reached $86 \pm 1 \%$ and $81 \pm 1 \%(p=0.433)$ of 194 the values achieved during two-leg cycling for power and endurance athletes, respectively, 195 with no difference between sexes $(p=0.252)$. Power $(W)$ at $\mathrm{VO}_{2}$ Peak $_{1-\text { leg }}$ was not significantly 196 different between sexes or disciplines whether normalised to body mass or not ( $p>0.05$ in all 197 cases). The ratio of $\mathrm{VO}_{2} \mathrm{Peak}_{1-\text { leg }}$ to $\mathrm{VO}_{2}$ Peak $_{2 \text {-leg }}$ did not differ significantly between disciplines $198(p=0.404)$ or sexes $(p=0.959)$. 
200

201

202

203

204

205

206

207

208

209

210

211

212

213

214

215

216

217

218

219

220

221

222

223

224

225

226

227

228

229

230

231

\section{Ratio of aerobic to anaerobic power}

There was no significant difference $(p=0.261)$ between men $(7.1 \pm 0.5 \%)$ and women $(8.4 \pm 0.6 \%)$ in the power at $\mathrm{VO}_{2} \mathrm{Peak}_{2-\text { leg }}$ as a fraction of the jumping power. The same applied to the power at peak fat oxidation that was $3.4 \pm 0.4 \%$ of power achieved during a vertical jump in both women and men $(p=0.589)$. The power $(W)$ at $\mathrm{VO}_{2}$ Peak $_{2}$-leg as a fraction of that achieved during a vertical jump was higher $(p=0.002)$ in endurance $(9.2 \pm 0.6 \%)$ than power athletes $(6.6 \pm 0.4 \%)$. The power $(\mathrm{W})$ at peak fat oxidation as a fraction of the jumping power was higher $(p=0.007)$ in endurance $(4.1 \pm 0.4 \%)$ than in power athletes $(2.7 \pm 0.3 \%)$.

\section{Age-related changes in aerobic and anaerobic power}

In table 3 it can be seen that age was the primary determinant of jumping power and $\mathrm{VO}_{2}$ Peak $_{2-\mathrm{leg}}$, both in absolute terms and when normalised to body mass. Sex was the second factor determining absolute jump power and $\mathrm{VO}_{2} \mathrm{Peak}_{2 \text {-leg, }}$ but discipline was more important than sex when jump power and $\mathrm{VO}_{2}$ Peak $_{2}$-leg were normalised to body mass (Table 3 ). For absolute FATmax there was a significant effect of age, but normalised to body mass the FATmax $\left(\mathrm{mL} \cdot \mathrm{kg}^{-1} \cdot \mathrm{min}^{-1}\right)$ was determined solely by athletic discipline (Table 3$)$.

The aerobic:anaerobic power ratio was not significantly affected by age or sex, but was higher in endurance than power athletes $(p=0.001$; Table 2$)$. However, the ratio of power at FATmax to that at $\mathrm{VO}_{2}$ Peak ${ }_{2}$-leg was not affected by age, discipline or sex. The $\mathrm{VO}_{2}$ Peak $_{1-l e g}: \mathrm{VO}_{2}$ Peak $_{2-}$ leg ratio was not significantly affected by age, sex or discipline.

Absolute jumping power (W) (7.4\% per decade, $\mathrm{p}<0.001)$, relative jumping power $(\mathrm{W} / \mathrm{kg})$ (9.4\% per decade, $\mathrm{p}<0.001$, Fig. $2 \mathrm{~A})$, absolute $\mathrm{VO}_{2}$ Peak $_{2 \text {-leg }}\left(\mathrm{L} \cdot \mathrm{min}^{-1}\right)(11.2 \%$ per decade, $\mathrm{p}<0.001)$, relative $\mathrm{VO}_{2}$ Peak 2 -leg $\left(\mathrm{mL} \cdot \mathrm{kg}^{-1} \cdot \mathrm{min}^{-1}\right)(9.0 \%$ per decade, $\mathrm{p}<0.01$, Fig. $2 \mathrm{~B})$ and $\mathrm{VO}_{2}$ Peak $_{1-\text { leg }}\left(L \cdot \mathrm{min}^{-1}\right)(14.2 \%$ per decade, $\mathrm{p}<0.001)$ declined with advancing age.

\section{Discussion}

It is widely acknowledged that regular exercise is an effective way to combat or ameliorate the declines in physical function that occur with advancing age. Cross-sectional data from 3790-year-old master athletes in the present study suggests that both peak anaerobic and 
232 aerobic power decline by around $7-14 \%$ per decade and that this trajectory did not differ 233 between power or endurance athletes. Even though master athletes perform better than age234 matched non-athletes [30], the present results suggest age-related changes in the 235 neuromuscular and cardiopulmonary systems progress at similar rates, regardless of power or endurance competitive specialisations.

237 The master athletes in the present study were amongst the most athletic Europeans for their 238 age, as reflected by the cohort mean AGP of $82.7 \pm 2.2 \%$. To put this into context, a 75 -year239 old male marathon time of $80 \%$ AGP is $3 \mathrm{~h}: 46 \mathrm{~m}: 53 \mathrm{~s}$ and the $100 \mathrm{~m}$ sprint time is $16: 50 \mathrm{~s}$. 240 Despite these high achievements, physiological function clearly declined with increasing age.

Power vs. endurance athletes

243 The counter-movement jump is indicative of maximal anaerobic power ${ }^{[31]}$. In line with 244 previous observations ${ }^{[15,20]}$ we observed that the jumping (anaerobic) power per body mass 245 of power athletes was 33\% higher than that of endurance runners, reflecting the expected 246 greater muscle power in power than endurance athletes. A novel contribution of our study is 247 that we also collected measurements of peak aerobic power for the same participants and 248 can compare across age and across disciplines. In healthy young adults, $\mathrm{VO}_{2} \mathrm{Peak}_{2 \text {-leg }}$ during

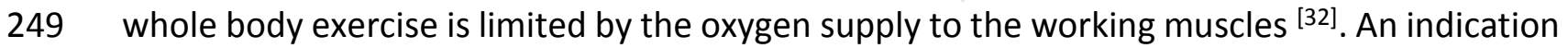
250 of the extent of the central limitation can be gained from the ratio of one- to two-leg cycling $251 \mathrm{VO}_{2}$ Peak ${ }^{[29]}$. The similar ratio in endurance and power athletes suggests that the 252 cardiovascular limitations to two-leg cycling are similar in both athletic groups, despite the 253 very different competitive specialisation of these athletes.

255 The $\mathrm{VO}_{2}$ Peak $_{1-\text { leg }}\left(\mathrm{L} \cdot \mathrm{min}^{-1}\right)$ was similar for endurance and power athletes, despite the leg 256 muscle mass being larger for power athletes than for endurance runners ${ }^{[33]}$. This is most likely 257 due to the higher oxidative potential per unit muscle mass of endurance runners compared 258 with power athletes ${ }^{[34]}$ to compensate for lower muscle mass. In addition to the higher 259 oxidative capacity per unit muscle mass of endurance athletes ${ }^{[34]}$, we found up to $45 \%$ higher 260 rate of fatty acid oxidation per unit body mass in endurance than power athletes at exercise intensities of $30-70 \%$ of $\mathrm{VO}_{2}$ Peak $_{2}$-leg. In line with this, previous studies have shown a 262 significant increase in muscle mitochondrial enzymes and those of fatty acid metabolism 
263 following endurance training ${ }^{[35]}$. A higher rate of fat oxidation, as we observed for endurance 264 athletes, will make the muscle less dependent on glucose metabolism, sparing glycogen and 265 thereby increasing prolonged endurance performance ${ }^{[36]}$. Such an adaptation is not required 266 in power athletes who rely on anaerobic ATP generation from creatine phosphate and by 267 glycolysis for success in their discipline.

Interestingly, we found that the FATmax was higher in endurance than power athletes in men, 270 but not in women. Nevertheless, like in male $(r=0.828, p=0.011)$ we also observed in female $271(r=0.702, p=0.016)$ endurance athletes a correlation between body mass normalised FATmax and maximal aerobic capacity. Whatever the cause of the absence of a higher FATmax in the female endurance than power athletes, the FATmax appears to be related in both sexes and disciplines with maximal aerobic capacity.

275

276 Based on previously published jump data in masters sprinters ${ }^{[15]}$ and the $\mathrm{VO}_{2}$ Peak $_{2-\text { leg }}$ data 277 from endurance runners ${ }^{[42]}$, it was estimated that the proportion of total power that can be 278 generated through aerobic processes is around $30 \%$ of the peak anaerobic power [17]. This 279 value is higher than the $9 \%$ and $7 \%$ we found in endurance and power athletes, respectively. 280 The discrepancy may be due to the previous study deriving maximal anaerobic power data 281 from master sprinters and the $\mathrm{VO}_{2} \mathrm{Peak}_{2}$-leg data from a different set of specifically-trained 282 master endurance runners, while we calculated this ratio directly from measurements completed in the same individuals. The difference between 2-legged jumping and cycling is also apparent, in that cycling is an alternating limb exercise where every time only one leg 285 produces power and little of the power is gained from musculo-tendinous elasticity, compared to the 2-legged jump ${ }^{[43]}$. In any case, the aerobic power is only a small fraction of the anaerobic power and this was true regardless of endurance or power training 288 specialisations. The fraction of anaerobic power that can be generated the peak rate of fatty acid oxidation is even smaller, at $4 \%$ for endurance and just $3 \%$ for power athletes.

\section{Ageing in power and endurance athletes}

292 We expected that the anaerobic power would be better preserved during ageing in power 293 than endurance athletes, while the $\mathrm{VO}_{2} \mathrm{Peak}_{2}$-leg would be better preserved in endurance 
294 athletes. This is important as throughout life both anaerobic power ${ }^{[2]}$ and $\mathrm{VO}_{2} \mathrm{Peak}_{2-\mathrm{leg}}$ 295 decrease with increasing age ${ }^{[3]}$. In this context it was noted that throughout the life span, the 296 anaerobic power is larger in power athletes ${ }^{[15]}$ and aerobic power larger in endurance 297 athletes ${ }^{[16]}$ than age-matched non-athletes. Similar to previous studies, we found that the 298 rate of decline in peak jump power ${ }^{[15,20]}$ was similar in power and endurance athletes. The 299 same applied to the decline in $\mathrm{VO}_{2}$ Peak $_{2-\mathrm{leg}}$, which corresponds with other studies that 300 showed that the age-related rate of decline in $\mathrm{VO}_{2} \mathrm{Peak}_{2-\mathrm{leg}}$ was similar in endurance runners 301 and non-athletes ${ }^{[42,44]}$, even though the absolute decline is faster in athletes ${ }^{[16]}$. This suggests 302 that there is an inherent ageing process that cannot be delayed.

303 As a consequence of the similar rates of decline in anaerobic and aerobic power in both power 304 athletes and endurance runners, and men and women, the aerobic:anaerobic power ratio 305 remained constant with ageing and higher in endurance than power athletes. This 306 corresponds with the similar relative age-related decrements in running speed records of 307 endurance and power master athletes ${ }^{[17]}$. This consistent pattern of ageing appears to apply 308 to the performance in many other athletic disciplines, including swimmers ${ }^{[45]}$. The age309 related decrement is not limited to aerobic and anaerobic power, but also applies to the 310 maximal rate of fat oxidation. While older untrained adults have lower rates of fatty acid 311 oxidation than younger adults ${ }^{[37]}$, the ratio of workload at maximal rate of fatty acid oxidation 312 to workload at $\mathrm{VO}_{2}$ Peak $_{2}$-leg did not show an age-related decline in either discipline or sex in 313 our study. These proportional declines in work at maximal fatty acid oxidation, and maximal 314 aerobic and anaerobic power suggest that physiological systems determining these 315 parameters age proportionally, irrespective of athletic discipline, or even being an athlete at 316 all.

317 Such a proportional age-related decline in physiological systems is also reflected by the stable 318 ratio of one-leg to two-leg performance across the ages, irrespective of discipline. This 319 indicates that in both endurance and power athletes the cardiovascular system remains the 320 main limitation of whole body $\mathrm{VO}_{2}$ Peak $_{2-\text { leg }}$ during ageing and that the systems involved in 321 oxygen utilisation age proportionally ${ }^{[16]}$. Thus in older endurance and power athletes, the 322 oxygen delivering and consuming systems do not violate the principle of symmorphosis that 323 assumes that structures are matched to functional demands ${ }^{[46]}$. 


\section{Study limitations}

325 In measurement of $\mathrm{VO}_{2}$ peak ${ }_{2-\text { leg, }}$ athletes were stopped when they exceeded by more than

$32610 \mathrm{bpm}$ the age-predicted maximal heart rate. It is possible that athletes did not achieve true 327 maximal oxygen uptake in some cases even if their true maximal heart rate was greater than 328 the methodological constraint that we applied for study governance. However, this bias 329 applied to both sexes and to both power and endurance athletes equally. The present study 330 was a cross-sectional design and recruitment targeted very high performing athletes, which 331 constrained recruitment to relatively low overall sample sizes, although this is commonplace 332 for studies of high performing athletes and the results provide new insights into a model of 333 ageing which is at the peak of physiological performance ${ }^{[7]}$. While it is possible that the 334 physiological profiles of the athletes are the product of heritable pre-disposition, the intensive 335 exercise training programmes undoubtedly contributed to their outstanding physical 336 capabilities. Furthermore, it is not possible to determine whether the divergent profiles of 337 endurance and power athletes are due to their specific training programmes and/or to 338 heritable factors.

339 Perspective

340 Master power athletes appear to exhibit a higher relative anaerobic power and lower relative 341 aerobic power than master endurance athletes. However, the relative (\%) annual decline in 342 anaerobic power and aerobic power is similar in both athletic groups. The present data also 343 suggests that during ageing there is a proportional decline in the power at the maximal rate 344 of fat oxidation, irrespective of discipline and sex. It thus appears that there is an inherent, 345 unavoidable (at least by exercise) ageing process that affects cardiopulmonary and 346 neuromuscular systems important for exercise performance. Despite aerobic and anaerobic 347 power declines with advancing age in masters athletes, the benefits of exercise during aging 348 are evident as higher physical function than in age-matched non-athletes ${ }^{[30]}$.

\section{References}

351 1. Degens, H., The origin of senescence and death; an evolutionary enigma. Creation 352 Research Society Quarterly, 2008. 44: p. 280-286.

353 2. Runge, M., Rittweger, J., Russo, C.R., Schiessl, H.,Felsenberg, D., Is muscle power 354 output a key factor in the age-related decline in physical performance? A comparison 
of muscle cross section, chair-rising test and jumping power. Clin Physiol Funct Imaging, 2004. 24(6): p. 335-40.

3. Fleg, J.L.,Lakatta, E.G., Role of muscle loss in the age-associated reduction in VO2 max. J Appl Physiol (1985), 1988. 65(3): p. 1147-51.

4. Degens, H.,Alway, S.E., Control of muscle size during disuse, disease, and aging. Int J Sports Med, 2006. 27(2): p. 94-9.

5. Ingram, D.K., Age-related decline in physical activity: generalization to nonhumans. Med Sci Sports Exerc, 2000. 32(9): p. 1623-9.

6. Hannam, K., Deere, K.C., Hartley, A., Clark, E.M., Coulson, J., Ireland, A., Moss, C., Edwards, M.H., Dennison, E., Gaysin, T., Cooper, R., Wong, A., McPhee, J.S., Cooper, C., Kuh, D.,Tobias, J.H., A novel accelerometer-based method to describe day-to-day exposure to potentially osteogenic vertical impacts in older adults: findings from a multi-cohort study. Osteoporos Int, 2017. 28(3): p. 1001-1011.

7. Hawkins, S.A., Wiswell, R.A.,Marcell, T.J., Exercise and the master athlete - A model of successful aging? Journals of Gerontology Series a-Biological Sciences and Medical Sciences, 2003. 58(11): p. 1009-1011.

8. Cheng, S., Degens, H., Evans, M., Cheng, S.M., Selanne, H., Rittweger, J., Heinonen, A., Suominen, H., Strandberg, T., Alen, M.,Korhonen, M.T., What Makes a 97-YearOld Man Cycle 5,000 km a Year? Gerontology, 2016. 62(5): p. 508-12.

9. Faulkner, J.A., Davis, C.S., Mendias, C.L.,Brooks, S.V., The aging of elite male athletes: age-related changes in performance and skeletal muscle structure and function. Clin J Sport Med, 2008. 18(6): p. 501-7.

10. Kettunen, J.A., Kujala, U.M., Kaprio, J.,Sarna, S., Health of master track and field athletes: a 16-year follow-up study. Clin J Sport Med, 2006. 16(2): p. 142-8.

11. Pollock, R.D., Carter, S., Velloso, C.P., Duggal, N.A., Lord, J.M., Lazarus, N.R.,Harridge, S.D., An investigation into the relationship between age and physiological function in highly active older adults. J Physiol, 2015. 593(3): p. 657-80.

12. McPhee, J.S., French, D.P., Jackson, D., Nazroo, J., Pendleton, N.,Degens, H., Physical activity in older age: perspectives for healthy ageing and frailty. Biogerontology, 2016. 17(3): p. 567-80.

13. Blair, S.N., Kohl, H.W., Paffenbarger, R.S., Clark, D.G., Cooper, K.H.,Gibbons, L.W., Physical fitness and all-cause mortality. A prospective study of healthy men and women. JAMA, 1989. 262(17): p. 2395-401.

14. Evans, W.J.,Campbell, W.W., Sarcopenia and age-related changes in body composition and functional capacity. J Nutr, 1993. 123(2 Suppl): p. 465-8.

15. Michaelis, I., Kwiet, A., Gast, U., Boshof, A., Antvorskov, T., Jung, T., Rittweger, J.,Felsenberg, D., Decline of specific peak jumping power with age in master runners. J Musculoskelet Neuronal Interact, 2008. 8(1): p. 64-70.

16. Tanaka, H., Desouza, C.A., Jones, P.P., Stevenson, E.T., Davy, K.P.,Seals, D.R., Greater rate of decline in maximal aerobic capacity with age in physically active vs. sedentary healthy women. J Appl Physiol (1985), 1997. 83(6): p. 1947-53.

17. Rittweger, J., di Prampero, P.E., Maffulli, N.,Narici, M.V., Sprint and endurance power and ageing: an analysis of master athletic world records. Proceedings of the Royal Society B-Biological Sciences, 2009. 276(1657): p. 683-689.

18. Ganse, B., Ganse, U., Dahl, J.,Degens, H., Linear Decrease in Athletic Performance During the Human Life Span. Frontiers in Physiology, 2018. 9(1100). 
401

402

403

404

405

406

407

408

409

410

411

412

413

414

415

416

417

418

419

420

421

422

423

424

425

426

427

428

429

430

431

432

433

434

435

436

437

438

439

440

441

442

443

444

445

446

447

19. Hamill, J., Bates, B.T., Knutzen, K.M.,Sawhill, J.A., Variations in ground reaction force parameters at different running speeds. Human Movement Science, 1983. 2(1): $p$. 47-56.

20. Grassi, B., Cerretelli, P., Narici, M.V.,Marconi, C., Peak anaerobic power in master athletes. Eur J Appl Physiol Occup Physiol, 1991. 62(6): p. 394-9.

21. Kyröläinen, H.,Komi, P.V., Neuromuscular performance of lower limbs during voluntary and reflex activity in power- and endurance-trained athletes. European Journal of Applied Physiology and Occupational Physiology, 1994. 69(3): p. 233-239.

22. Costill, D.L., Thomason, H.,Roberts, E., Fractional utilization of the aerobic capacity during distance running. Med Sci Sports, 1973. 5(4): p. 248-52.

23. Saltin, B.,Astrand, P.O., Maximal oxygen uptake in athletes. Journal of Applied Physiology, 1967. 23(3): p. 353-358.

24. World Medical Association, World Medical Association Declaration of Helsinki: ethical principles for medical research involving human subjects. JAMA, 2013. 310(20): p. 2191-4.

25. Cavagna, G.A., Force platforms as ergometers. J Appl Physiol, 1975. 39(1): p. 174-9.

26. Peronnet, F.,Massicotte, D., Table of nonprotein respiratory quotient: an update. Can J Sport Sci, 1991. 16(1): p. 23-9.

27. Mortensen, S.P., Dawson, E.A., Yoshiga, C.C., Dalsgaard, M.K., Damsgaard, R., Secher, N.H.,Gonzalez-Alonso, J., Limitations to systemic and locomotor limb muscle oxygen delivery and uptake during maximal exercise in humans. J Physiol, 2005. 566(Pt 1): p. 273-85.

28. Richardson, R.S., Grassi, B., Gavin, T.P., Haseler, L.J., Tagore, K., Roca, J.,Wagner, P.D., Evidence of $\mathrm{O} 2$ supply-dependent $\mathrm{VO} 2$ max in the exercise-trained human quadriceps. J Appl Physiol (1985), 1999. 86(3): p. 1048-53.

29. McPhee, J.S., Williams, A.G., Stewart, C., Baar, K., Schindler, J.P., Aldred, S., Maffulli, N., Sargeant, A.J.,Jones, D.A., The training stimulus experienced by the leg muscles during cycling in humans. Experimental physiology, 2009. 94(6): p. 684-94.

30. Korhonen, M.T., Cristea, A., Alén, M., Häkkinen, K., Sipilä, S., Mero, A., Viitasalo, J.T., Larsson, L.,Suominen, H., Aging, muscle fiber type, and contractile function in sprinttrained athletes. J Appl Physiol (1985), 2006. 101(3): p. 906-17.

31. Nummela, A., Alberts, M., Rijntjes, R.P., Luhtanen, P.,Rusko, H., Reliability and validity of the maximal anaerobic running test. Int J Sports Med, 1996. 17 Suppl 2: p. S97-102.

32. Saltin, B.,Calbet, J.A., Point: in health and in a normoxic environment, VO2 max is limited primarily by cardiac output and locomotor muscle blood flow. J Appl Physiol (1985), 2006. 100(2): p. 744-5.

33. Piasecki, J., McPhee, J.S., Hannam, K., Deere, K.C., Elhakeem, A., Piasecki, M., Degens, H., Tobias, J.H.,Ireland, A., Hip and spine bone mineral density are greater in master sprinters, but not endurance runners compared with non-athletic controls. Arch Osteoporos, 2018. 13(1): p. 72.

34. Dubouchaud, H., Butterfield, G.E., Wolfel, E.E., Bergman, B.C.,Brooks, G.A., Endurance training, expression, and physiology of $L D H, M C T 1$, and MCT4 in human skeletal muscle. Am J Physiol Endocrinol Metab, 2000. 278(4): p. E571-9.

35. Coggan, A.R., Spina, R.J., Rogers, M.A., King, D.S., Brown, M., Nemeth, P.M.,Holloszy, J.O., Histochemical and Enzymatic Characteristics of Skeletal-Muscle in Master Athletes. Journal of applied physiology, 1990. 68(5): p. 1896-1901. 
448

449

450

451

452

453

454

455

456

457

458

459

460

461

462

463

464

465

466

467

468

469

470

471

472

473

474

475

476

477

478

479

480

481

482

483

484

36. Van Der Vusse, G.J.,Reneman, R.S., Lipid Metabolism in Muscle, in Comprehensive Physiology. 2010, John Wiley \& Sons, Inc.

37. Sial, S., Coggan, A.R., Carroll, R., Goodwin, J.,Klein, S., Fat and carbohydrate metabolism during exercise in elderly and young subjects. Am J Physiol, 1996. 271(6 Pt 1): p. E983-9.

38. Levadoux, E., Morio, B., Montaurier, C., Puissant, V., Boirie, Y., Fellmann, N., Picard, B., Rousset, P., Beaufrere, B.,Ritz, P., Reduced whole-body fat oxidation in women and in the elderly. Int J Obes Relat Metab Disord, 2001. 25(1): p. 39-44.

39. Abildgaard, J., Pedersen, A.T., Green, C.J., Harder-Lauridsen, N.M., Solomon, T.P., Thomsen, C., Juul, A., Pedersen, M., Pedersen, J.T., Mortensen, O.H., Pilegaard, H., Pedersen, B.K.,Lindegaard, B., Menopause is associated with decreased whole body fat oxidation during exercise. Am J Physiol Endocrinol Metab, 2013. 304(11): $p$. E1227-36.

40. Oliveira, P.J., Carvalho, R.A., Portincasa, P., Bonfrate, L.,Sardao, V.A., Fatty Acid Oxidation and Cardiovascular Risk during Menopause: A Mitochondrial Connection? J Lipids, 2012. 2012: p. 365798.

41. Calles-Escandón, J., Arciero, P.J., Gardner, A.W., Bauman, C.,Poehlman, E.T., Basal fat oxidation decreases with aging in women. J Appl Physiol (1985), 1995. 78(1): p. 26671.

42. Wiswell, R.A., Hawkins, S.A., Jaque, S.V., Hyslop, D., Constantino, N., Tarpenning, K., Marcell, T.,Schroeder, E.T., Relationship between physiological loss, performance decrement, and age in master athletes. Journals of Gerontology Series a-Biological Sciences and Medical Sciences, 2001. 56(10): p. M618-M626.

43. Luhtanen, P.,Komi, P.V., Force-, power-, and elasticity-velocity relationships in walking, running, and jumping. Eur J Appl Physiol Occup Physiol, 1980. 44(3): p. 27989.

44. Pimentel, A.E., Gentile, C.L., Tanaka, H., Seals, D.R.,Gates, P.E., Greater rate of decline in maximal aerobic capacity with age in endurance-trained than in sedentary men. J Appl Physiol (1985), 2003. 94(6): p. 2406-13.

45. Berthelot, G., Len, S., Hellard, P., Tafflet, M., Guillaume, M., Vollmer, J.C., Gager, B., Quinquis, L., Marc, A.,Toussaint, J.F., Exponential growth combined with exponential decline explains lifetime performance evolution in individual and human species. Age (Dordr), 2012. 34(4): p. 1001-9.

46. Hoppeler, H.,Weibel, E.R., Structural and functional limits for oxygen supply to muscle. Acta Physiol Scand, 2000. 168(4): p. 445-56. 


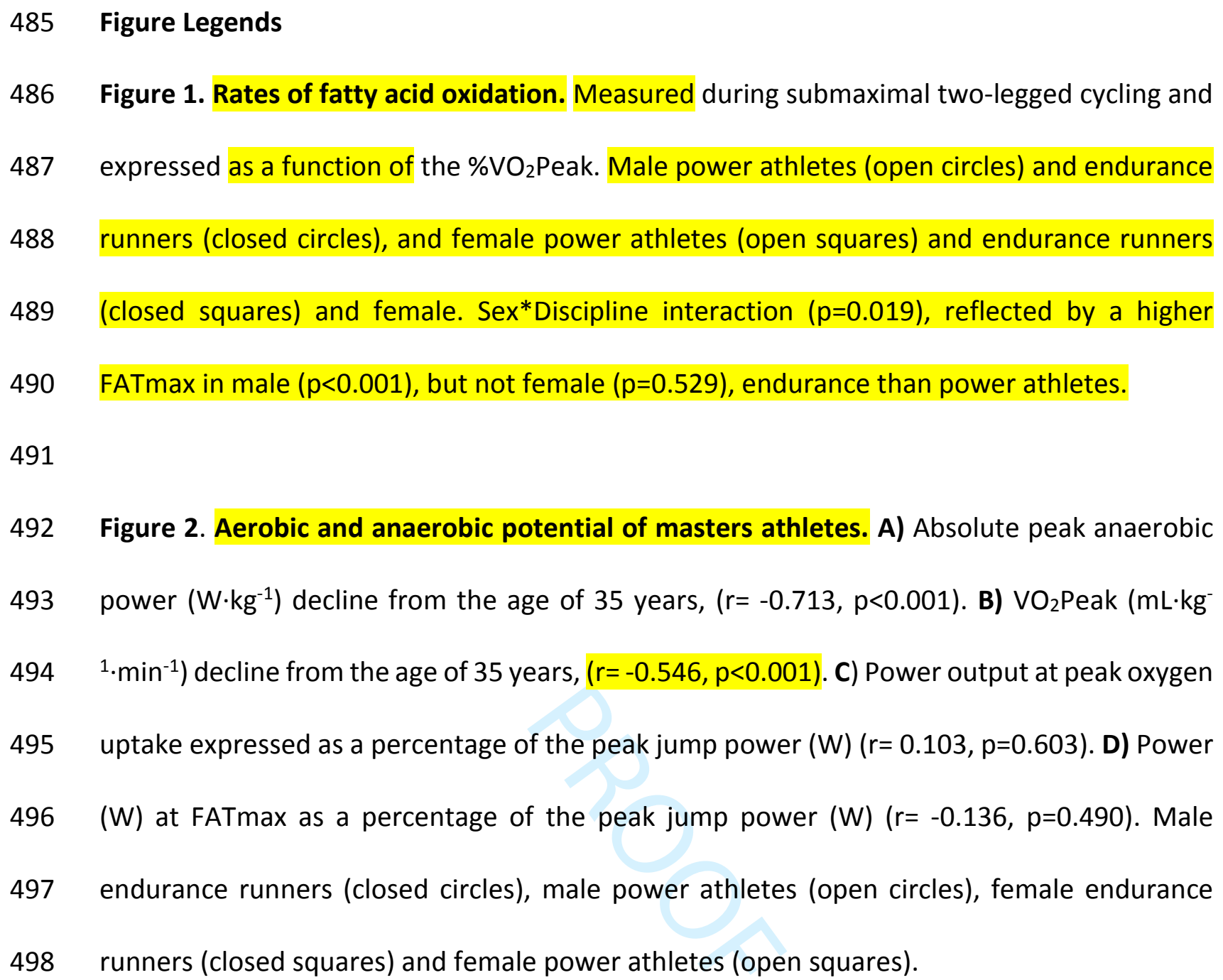


Table 1: Characteristics of participants separated by discipline and sex.

\begin{tabular}{|c|c|c|c|c|c|c|}
\hline $\begin{array}{l}\text { Running } \\
\text { Discipline }\end{array}$ & $\mathbf{N}$ & $\begin{array}{c}\text { Age } \\
\text { (years) }\end{array}$ & $\begin{array}{c}\text { Height } \\
\text { (m) }\end{array}$ & $\begin{array}{l}\text { BM } \\
\text { (kg) }\end{array}$ & $\begin{array}{c}\text { BMI } \\
\left(\mathrm{kg} \cdot \mathrm{m}^{-2}\right)\end{array}$ & AGP (\%) \\
\hline \multirow[t]{2}{*}{ Endurance } & $8 \hat{\sigma}$ & $62 \pm 5$ & $1.74 \pm 0.04$ & $66.1 \pm 3.6$ & $21.8 \pm 1.1$ & $86.3 .0 \pm 5.5$ \\
\hline & 11 우 & $58 \pm 3$ & $1.63 \pm 0.02^{*}$ & $54.9 \pm 1.4^{*}$ & $20.7 \pm 0.5$ & $79.6 \pm 3.8$ \\
\hline \multirow[t]{2}{*}{ Power } & 11 ఠ & $58 \pm 5$ & $1.79 \pm 0.03$ & $78.6 \pm 2.9^{\dagger}$ & $24.4 \pm 0.5^{+}$ & $78.1 \pm 4.9$ \\
\hline & 9 우 & $63 \pm 6$ & $1.63 \pm 0.02^{*}$ & $61.4 \pm 2.7^{*,+}$ & $23.0 \pm 0.6^{+}$ & $88.1 \pm 3.7$ \\
\hline
\end{tabular}

BM: body mass; BMI: body mass index; AGP: Age-graded performance. Data are shown as mean \pm SEM. *indicates significant sex difference, tindicates significant difference between disciplines. 
Table 2: Muscle aerobic and anaerobic power of participants separated by discipline and sex

\begin{tabular}{|c|c|c|c|c|c|c|c|c|c|c|c|c|c|c|c|}
\hline $\begin{array}{l}\text { 6Running } \\
7 \text { Discipline } \\
8 \\
9\end{array}$ & Sex & $\mathrm{JP}(\mathrm{W})$ & $\begin{array}{l}\mathrm{JP} / \mathrm{BM} \\
\left(\mathrm{W} \cdot \mathrm{Kg}^{-1}\right)\end{array}$ & $\begin{array}{l}\text { Velocity } \\
\text { take-off } \\
\left(\mathrm{m} \cdot \mathrm{s}^{-1}\right)\end{array}$ & $\begin{array}{c}\mathrm{VO}_{2} \text { Peak }_{2 \text {-leg }} \\
\left(\mathrm{L} \cdot \mathrm{min}^{-1}\right)\end{array}$ & $\begin{array}{c}\mathrm{VO}_{2} \text { Peak }_{2-\operatorname{leg}} / \mathrm{BM} \\
\left(\mathrm{mL} \cdot \mathrm{kg}^{-1} \cdot \mathrm{min}^{-1}\right)\end{array}$ & $\begin{array}{c}\text { Power } \\
\text { VO }_{2} \text { Peak }_{2-\text { leg }} \\
\text { (W) }\end{array}$ & $\begin{array}{c}\text { HR VO }{ }_{2} \text { Peak }_{2-\text { leg }} \\
\text { (bpm) }\end{array}$ & $\begin{array}{ll} & \text { FATmax } \\
\left(g \cdot \min ^{-1}\right)\end{array}$ & $\begin{array}{l}\text { FATmax/BM } \\
\left(\mathrm{mg} \cdot \mathrm{kg}^{-1} \cdot \mathrm{min}^{-1}\right)\end{array}$ & $\begin{array}{c}\text { Power } \\
\text { FATmax } \\
\text { (W) }\end{array}$ & $\begin{array}{l}\text { Aer:Anaer } \\
\text { Power (\%) }\end{array}$ & $\begin{array}{c}\mathrm{VO}_{2} \text { Peak }_{1-\mathrm{leg}} \\
\left(\mathrm{L} \cdot \mathrm{min}^{-1}\right)\end{array}$ & $\begin{array}{c}\text { Power } \\
\text { vo }_{2} \text { Peak }_{1-\text { leg }} \\
\text { (W) }\end{array}$ & $\begin{array}{l}\mathrm{VO}_{2} \text { Peak }_{1 \text {-leg: }} \\
\text { VO }_{2} \text { Peak }\end{array}$ \\
\hline $\begin{array}{l}10 \\
\text { Endurance } \\
12\end{array}$ & $\sigma^{\pi}$ & $\begin{array}{c}3081 \pm 453 \\
(n=6)\end{array}$ & $45.3 \pm 4.7$ & $2.33 \pm 0.12$ & $3.62 \pm 0.38$ & $54.2 \pm 2.9$ & $259 \pm 43$ & $152 \pm 8$ & $0.61 \pm 0.09$ & $9.12 \pm 0.96$ & $149 \pm 30$ & $8.94 \pm 0.47$ & $\begin{array}{c}2.83 \pm 0.62 \\
(n=4)\end{array}$ & $173 \pm 50$ & $0.78 \pm 0.04$ \\
\hline $\begin{array}{l}13 \\
14 \\
15\end{array}$ & & $\begin{array}{c}1985 \pm 179^{*} \\
(n=8)\end{array}$ & $35.5 \pm 2.5$ & $2.10 \pm 0.11^{*}$ & $2.35 \pm 0.18^{*}$ & $42.9 \pm 3.4$ & $188 \pm 16^{*}$ & $152 \pm 5$ & $0.39 \pm 0.04$ & $7.07 \pm 0.81$ & $84 \pm 12^{*}$ & $9.34 \pm 0.92$ & $\begin{array}{c}1.95 \pm 0.27 \\
(n=5)\end{array}$ & $108 \pm 12$ & $0.84 \pm 0.04$ \\
\hline $\begin{array}{l}16_{\text {Sprint }} \\
17\end{array}$ & $\sigma^{\pi}$ & $\begin{array}{c}4696 \pm 432^{+} \\
(n=8)\end{array}$ & $56.9 \pm 3.8^{\dagger} 2$ & $2.75 \pm 0.11^{+}$ & $3.17 \pm 0.26$ & $40.0 \pm 2.7^{+}$ & $258 \pm 28$ & $157 \pm 5$ & $0.38 \pm 0.03^{+}$ & $4.75 \pm 0.30^{+}$ & $126 \pm 14$ & $5.98 \pm 0.42^{+}$ & $\begin{array}{c}2.25 \pm 0.26 \\
(n=5)\end{array}$ & $123 \pm 30$ & $0.79 \pm 0.04$ \\
\hline $\begin{array}{l}18 \\
19 \\
20\end{array}$ & & $\begin{array}{c}2963 \pm 465^{*},+ \\
(n=7)\end{array}$ & $47.9 \pm 7.7^{+}$ & $2.23 \pm 0.12^{*,+}$ & $2.54 \pm 0.16^{*}$ & $41.7 \pm 3.1^{+}$ & $190 \pm 12^{*}$ & $164 \pm 5$ & $0.38 \pm 0.04 \rrbracket$ & $6.32 \pm 0.82 \mathbf{\Lambda}$ & $81 \pm 13^{*}$ & $7.24 \pm 0.69^{+}$ & $\begin{array}{c}1.83 \pm 0.44 \\
(n=4)\end{array}$ & $93 \pm 21$ & $0.73 \pm 0.10$ \\
\hline
\end{tabular}

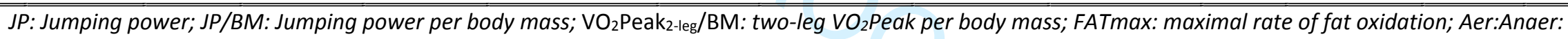

Aerobic:Anaerobic Power (\%); $\mathrm{VO}_{2}$ Peak $_{1-\mathrm{leg}}$ : $\mathrm{VO}_{2}$ Peak $_{2}$-eg: $\mathrm{VO}_{2}$ Peak of one- $v$ s $\mathrm{VO}_{2}$ Peak of two-leg cycling. Data are shown as mean \pm SEM. ${ }^{*}$ indicates significant sex difference,

tindicates significant difference between disciplines, $\mathbf{\Delta}^{\mathbf{\Delta}}$ indicates interaction between sex and discipline. 
Table 3: Stepwise linear regression between jumping power, aerobic capacity and rates of fatty acid oxidation with age, sex and discipline.

\begin{tabular}{|c|c|c|c|c|c|}
\hline $\begin{array}{l}\text { Jump Power } \\
\text { (W) }\end{array}$ & $\begin{array}{c}\text { Jump power } \\
\text { per body mass } \\
\left(\mathbf{W} \cdot \mathrm{kg}^{-1}\right)\end{array}$ & $\begin{array}{l}\mathrm{VO}_{2} \text { Peak } \\
\left(\mathrm{L} \cdot \mathrm{min}^{-1}\right)\end{array}$ & $\begin{array}{c}\mathrm{VO}_{2} \text { Peak per } \\
\text { body mass } \\
\left(\mathrm{mL} \cdot \mathrm{kg}^{-1} \cdot \mathrm{min}^{-1}\right)\end{array}$ & $\begin{array}{l}\text { FATmax } \\
\left(\mathrm{g} \cdot \mathrm{min}^{-1}\right)\end{array}$ & $\begin{array}{c}\text { FATmax per } \\
\text { body mass } \\
\left(\mathrm{mg}^{\prime} \mathrm{kg}^{-1} \cdot \mathrm{min}^{-1}\right)\end{array}$ \\
\hline A: $0.391^{* * *}$ & A: $0.490^{* * *}$ & $\mathrm{~A}: 0.374^{* * *}$ & A: $0.279^{* * *}$ & A: $0.132^{*}$ & D: $0.197^{* *}$ \\
\hline S: $0.652^{* * *}$ & D: $0.600^{* * *}$ & S: $0.637^{* * *}$ & D: $0.364^{* * *}$ & & \\
\hline D: $0.789^{* * *}$ & S: $0.680^{* * *}$ & & & & \\
\hline
\end{tabular}




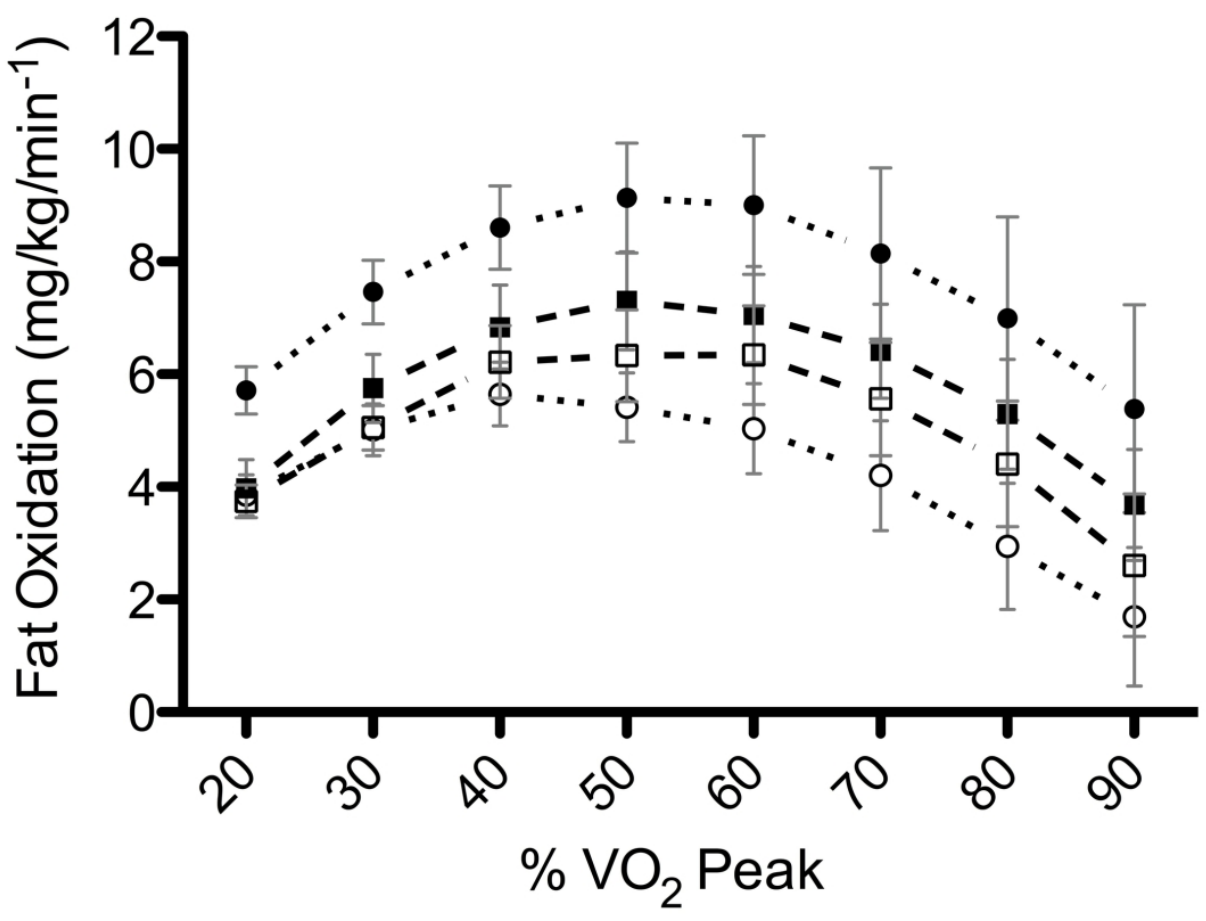

$98 \times 76 \mathrm{~mm}(600 \times 600 \mathrm{DPI})$ 

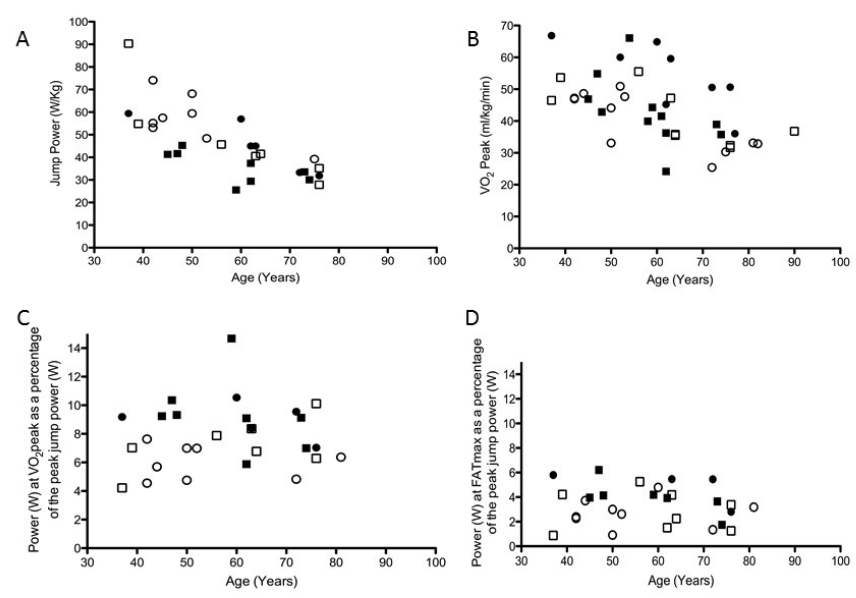

Figure 2

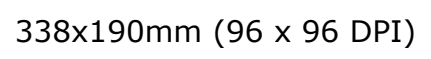




\title{
SIMILAR RELATIVE DECLINE IN AEROBIC AND ANAEROBIC POWER WITH AGE IN ENDURANCE AND SPRINT MASTER ATHLETES OF BOTH SEXES
}

\author{
Reviewer(s)' Comments to Author: \\ Reviewer: 1 \\ Comments to the Author \\ The authors have done very good work. The data is valuable because it is very difficult to \\ have such master athletes as subjects. The results are clear and important for practice. All \\ parts of the manuscript are of high scientific work.
}

The authors wish to thank the reviewer for their kind appraisal of the quality of our work and its place in the field of literature.

Reviewer: 2

Comments to the Author

This is an interesting manuscript which has studied the effects of age relate declines in in function in a cross-over - type design. It has done this by comparing explosive muscle function and aerobic capability in both sprint and endurance athletes. The paper provides some novel information about ageing that should be published.

The authors wish to thank the reviewer for their kind appraisal on the novelty of the work presented in our manuscript and their recommendation to publish. Thank you also for the suggestions listed below to improve the quality of the manuscript. All amendments made to the manuscript are highlighted in yellow and a line number given below.

Weakness / Suggestions for improvement

The number of subjects / master athletes is quite low.

The number of participants is lower than we would normally aim for when studying human physiology and ageing. This may limit the interpretation of the data. However, the participant group is highly specialised and belongs to the top performers of their age. This selection makes recruitment challenging indeed but at the same time we believe that this selection ensured a dataset that offers novel insights into the maximal achievable performance at a given age. Nevertheless, we have given the low number as a limitation in the study limitations section (lines 330333).

The classification of $800 \mathrm{~m}$ as a sprint even is dubious. What would happen if these were moved into the endurance category? Or a third category of middle distance athletes created? 


\begin{abstract}
If we created categories for power, middle and long distances, the group sizes would become 22, 9 and 8 respectively, and we believe these groups' sizes are too small. However, we do agree with the reviewer that $800 \mathrm{~m}$ is not classically defined as a power event and for this reason; we have re-classified $\geq 800 \mathrm{~m}$ as endurance and $\leq 400 \mathrm{~m}$ as power (Lines 89-91). This has made very little difference to the overall results (with the exception of a newfound sex * discipline interaction for FATmax measures; detail added to result section lines 184-188 and the discussion lines 269274).

Further to this, we have also re-classified the athletes as "power" and "endurance". The reason for this is that athletes in our cohort competed over multiple events (heptathlon, pentathlon, throwing etc). The AGP presented is for the athletes "best performance" (ie, the highest AGP from all of the performances at this competition).
\end{abstract}

The rationale for the 1 legged protocol needs to be made much clearer earlier in the paper.

The rationale for this protocol was detailed in the discussion. However, we have added further detail in the methods section (lines 130-135) as suggested.

It would be helpful if the details of each of the athletes (ages, events, physical characteristics etc) in a table (possibly as supplementary material?). This would be of utility to the reader.
We have discussed this amongst authors and decided that we cannot release the individual data as recommended. In the manuscript we have named the competition and the year. If we proceed to also release details of the specific event, ages and height etc., then it would theoretically be possible for somebody to look on the freely-available competitor listings and identify our study participants. This could be classed as a serious breach of participant confidentiality.

Measured maximum / peak heart rates should be included along with the caveat that there were imposed restrictions. How many reached VO2 max without reaching the cut off for $\max H R$ ?
We agree with this comment. The methodology has been fully described so that readers are aware of the methodological constraints affecting the data. 92\% of athletes tested reached (or mostly greatly exceeded) predicted VO2max as determined in Jones et al., Normal standards for an incremental progressive cycle ergometer test, 1985.
Further to this, one participant has been excluded from analysis (male, power athlete) due to premature termination of the 2-leg VO2peak test (49\% Predicted VO2peak/65\% max HR).

The Results section starting at line 24 does not seem to describe cover the main findings of Figure 1 in regard fat oxidation differences between two groups?

An additional line has been added to better explain the findings presented in figure 1. This section now describes that finding that FATmax occurs at a similar \%VO2peak 
between endurance and power athletes, however over the spectrum of exercise intensities, endurance athletes utilise significantly more fatty acid at given exercise intensities from 30-70\% VO2peak. Lines 184-188 